\title{
Interdisciplinary treatment of glioblastoma: Analysis of prognostic factors and treatment results in unselected patients
}

\author{
T. LANGSENLEHNER ${ }^{1, *}$, M. J. GROLL ${ }^{1}$, F. QUEHENBERGER ${ }^{2}$, F. PAYER ${ }^{3}$, M. MOKRY $^{4}$, K. S. KAPP ${ }^{1}$
}

${ }^{1}$ Department of Therapeutic Radiology and Oncology, Medical University of Graz, Austria; ${ }^{2}$ Institute for Medical Informatics, Statistics and Documentation, Medical University of Graz, Austria; ${ }^{3}$ Department of Neurology, Medical University of Graz, Austria; ${ }^{4}$ Department of Neurosurgery, Medical University of Graz, Austria

${ }^{*}$ Correspondence: tanja.langsenlehner@meduni-graz.at

Received April 16, 2012 / Accepted May 29, 2012

\begin{abstract}
Aim of the present study was to investigate survival rates of unselected patients with glioblastoma after multimodal treatment and estimation of prognostic factors.

Data of 189 patients (118 men; 71 women; median age: 59 years) with histologically confirmed glioblastoma treated from 1999 to 2009 were analyzed retrospectively. Complete tumor resection was performed in 99 patients (52\%), subtotal excision in 65 patients (34\%), and stereotactic biopsy in 25 patients (13\%). In 135 patients (71\%), residual tumors were detectable in post-surgical imaging. All patients underwent three-dimensional conformal radiotherapy of the tumor region in shrinkingfield technique to a total dose of 60 Gy. Beginning in 2002, 124 patients (66\%) received concomitant temozolomide (TMZ) treatment, 76 patients among them were additionally treated with adjuvant TMZ. After disease progression, 74 patients underwent salvage therapy (salvage chemotherapy, $\mathrm{n}=61$; local therapy, $\mathrm{n}=30$ ).

Actuarial 1- and 2- year progression-free survival (PFS) rates were $32 \%$ and $7 \%$, overall survival (OS) rates were $54 \%$ and $22 \%$, respectively. Without TMZ, 1 - and 2 - year OS rates were $47 \%$ and $11 \%$, with concomitant TMZ $57 \%$ and $28 \%$, and with concomitant and adjuvant TMZ 72\% and 44\%. In multivariate Cox proportional hazards regression models, age $(\mathrm{p}<0.001)$, extent of resection $(p=0.001)$, and TMZ $(p<0.001)$ were significantly associated with OS. Furthermore, a significant association between salvage therapy and improved survival was observed $(\mathrm{p}=0.020)$. RT with concomitant TMZ was well tolerated in the majority of patients and completed as scheduled in $78 \%$ of patients.

Multimodal treatment including extensive surgical resection, radiotherapy and chemotherapy significantly improves prognosis of patients with glioblastoma and is feasible with acceptable toxicity in routine practice. To achieve optimal results, close coordination among all disciplines is required.
\end{abstract}

Key words: glioblastoma, unselected patients, multimodal treatment, survival rates, prognostic factors

Glioblastoma (GBM) is the most common primary brain tumor and about 3 in 100,000 persons are newly diagnosed each year [1]. GBM is the second-most common cause of cancer related death in the young-adult age group and is associated with tremendous morbidity [2]. The most common presenting symptoms and signs for patients with GBM are progressive focal neurologic deficits, headaches, and seizures. Even though the reported incidence of many asymptomatic benign CNS tumors is increasing due to the increasing prevalence of neuroimaging, the aggressive growth of GBM usually precludes incidental discovery [3].
The majority of GBMs is located in the supratentorial compartments, but they also occur in the cerebellum, brainstem, and spinal cord. The vast majority of neoplastic cells is found within the tumor bed and within $2 \mathrm{~cm}$ of the enhancing borders, however, migrating cells can be found several centimeters away from the tumor and even in the contralateral hemisphere [4].

Despite intensive research, the prognosis for patients with GBM remains poor. Surgical intervention for GBM plays a key role for the diagnosis and prevention of symptoms due to mass effect. Mounting evidence suggests that more extensive surgical 
resections are associated with a longer life expectancy for patients with GBM $[5,6]$. However, due to the infiltrative nature of GBMs, complete tumor resections are difficult to achieve. Newer surgical techniques, such as fluorescence-guided resection and neuroendoscopic approaches, have been shown to enhance the macroscopic total resection of malignant gliomas $[7,8,9]$.

Radiotherapy (RT) has become part of the standard care. The ability to focus the beam and tailor it to the irregular contours of brain tumors and minimize the dose to nearby critical structures with intensity- modulated or image-guided techniques has greatly improved $[10,11,12,13]$. In addition, Temozolomide (TMZ), an alkylating agent with simple oral administration, has significantly improved overall survival in patients with malignant gliomas $[14,15]$. According to the randomized EORTC-NCIC trial published in 2005, the current standard of care for GBM is surgical resection followed by radiotherapy with concomitant and adjuvant TMZ [15].

However, in view of discrepancies concerning treatment and clinical characteristics, outcomes in unselected patient populations are often different from those achieved in study populations and need to be confirmed in routine clinical practice. The aim of the present retrospective analysis was to analyze outcome and toxicity in 189 patients treated for GBM at a high-volume single center. Furthermore, patient characteristics as well as tumor and treatment related factors were analyzed regarding their prognostic impact.

\section{Patients and methods}

Patients. Data of 189 consecutive patients (females: 71 (38\%); males: 118 (62\%) with glioblastoma irradiated between April 1999 and December 2009 at the Department of Therapeutic Radiology and Oncology, Medical University of Graz, were evaluated in this study.

In all patients, glioblastoma WHO grade 4 had been confirmed pathohistologically.

Median age at diagnosis was 59 years (mean: 59 years; range $22-88$ years). In all patients, preoperative tumour extension was determined based on MRI, CT scan or both. The vast majority of patients (92\%) presented a single lesion only. The median maximum tumor diameter was $4.5 \mathrm{~cm}$ (mean, $4.5 \mathrm{~cm}$; range $0.8-8.0 \mathrm{~cm}$ ).

The most frequently involved site was the temporal lobe $(46 \%)$. At the time of diagnosis, the presence of focal symptoms was the most frequent symptom. Incidental diagnosis, based on imaging performed without neurological symptoms, occurred in only 2 patients.

Treatment. Neurosurgical intervention preceded radiotherapy in all patients. 99 of 189 patients (52\%) had total tumor resections, and 65 patients (34\%) subtotal resections. In 25 patients (13\%), only stereotactic biopsy was performed. Post-surgical MRI/CT imaging was performed in 168 patients (89\%). In 135 patients $(71 \%)$, residual tumors (solid mass, $n=77$; marginal uptake of contrast media $\mathrm{n}=58$ ) were detected. Further details on patient and tumor characteristics are provided in table 1.
Median duration from surgery to the start of radiotherapy was 4 weeks (range, 2 - 28 weeks). Median Karnofsky Performance Score (KPS) prior to the start of radiotherapy was $80 \%$ (range, $30 \%-100 \%)$. In 44 patients $(23 \%)$, KPS was $<70 \%$, whereas 141 patients $(75 \%)$ had a KPS $\geq 70 \%$.

High energy photon beams (6 MV) were delivered after three- dimensional treatment planning in shrinking-field technique. The initial CTV included the residual T1 contrastenhancing tumor plus resection cavity and the peritumoral edema plus $2 \mathrm{~cm}$ and was treated to $50 \mathrm{~Gy}$ in 25 fractions delivered $5 \mathrm{x}$ weekly. After $50 \mathrm{~Gy}$, the boost volume, defined as the residual tumour plus resection cavity, was treated to a total dose of $60 \mathrm{~Gy}$ with single fraction doses of $2 \mathrm{~Gy}$.

Beginning in 2002, 124 patients (66\%), received systemic treatment with TMZ concomitantly 7 days each week from the first to the last day of radiotherapy at a dose of $75 \mathrm{mg} / \mathrm{m} 2$ per day. Additionally, 76 patients among them were administered

Table 1. Patient characteristics

\begin{tabular}{|c|c|}
\hline Characteristics & Number of patients, $\mathrm{n}(\%)$ \\
\hline \multicolumn{2}{|l|}{ Sex } \\
\hline Female & $71(38 \%)$ \\
\hline Male & $118(62 \%)$ \\
\hline \multicolumn{2}{|l|}{ Presenting symptoms } \\
\hline Focal symptoms & $106(56 \%)$ \\
\hline Cranial hypertension & $48(25 \%)$ \\
\hline Seizures & $32(17 \%)$ \\
\hline None & $2(1 \%)$ \\
\hline \multicolumn{2}{|l|}{ Involved site } \\
\hline Temporal & $77(46 \%)$ \\
\hline Frontal & $58(35 \%)$ \\
\hline Parietal & $59(36 \%)$ \\
\hline Occipital & $25(25 \%)$ \\
\hline \multicolumn{2}{|l|}{ Number of lesions } \\
\hline 1 & $174(92 \%)$ \\
\hline$\geq 2$ & $15(8 \%)$ \\
\hline \multicolumn{2}{|l|}{ Surgery } \\
\hline Total & $99(52 \%)$ \\
\hline Incomplete & $65(34 \%)$ \\
\hline Biospy & $25(13 \%)$ \\
\hline \multicolumn{2}{|l|}{ Residual tumor* } \\
\hline None & $33(18 \%)$ \\
\hline Margins & $58(31 \%)$ \\
\hline Solid mass & $77(41 \%)$ \\
\hline \multicolumn{2}{|l|}{ Karnofsky performance score } \\
\hline$\geq 70$ & $141(75 \%)$ \\
\hline$<70$ & $44(23 \%)$ \\
\hline \multicolumn{2}{|c|}{ Simultaneous Temozolomide } \\
\hline No & $64(34 \%)$ \\
\hline Yes & $124(66 \%)$ \\
\hline \multicolumn{2}{|l|}{ Adjuvant Temozolomide } \\
\hline No & $113(60 \%)$ \\
\hline Yes & $76(40 \%)$ \\
\hline \multicolumn{2}{|l|}{ Salvage therapy } \\
\hline No & $115(61 \%)$ \\
\hline Yes & $74(39 \%)$ \\
\hline
\end{tabular}

Abbreviations: $n=$ number of patients 

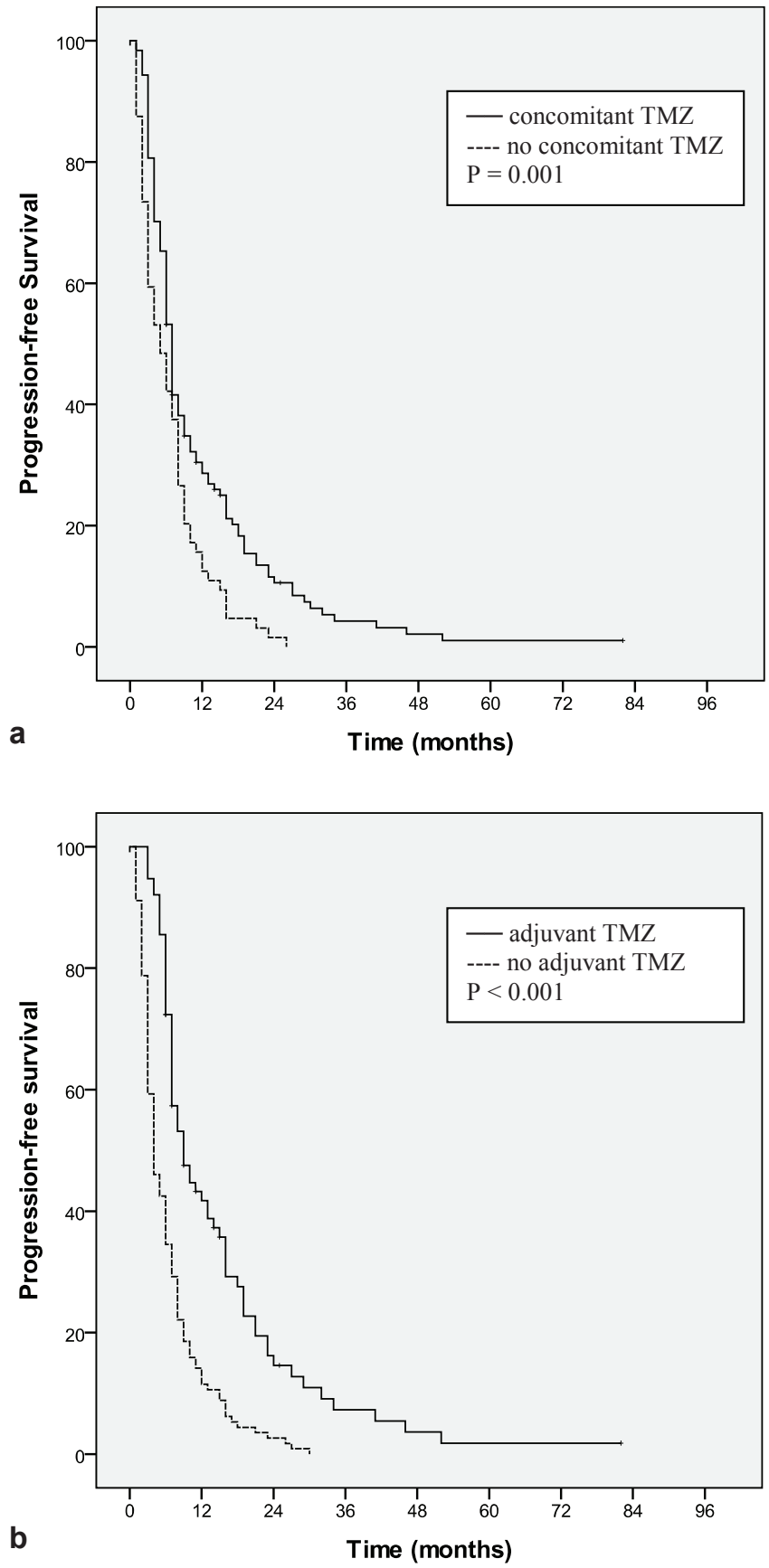

Figure 1a-b. Association of (a) concomitant TMZ and (b) adjuvant TMZ with Progression-free Survival.

adjuvant TMZ at 150 to $200 \mathrm{mg} / \mathrm{m} 2 / \mathrm{d}$ for 5 consecutive days every 4 weeks for a total of six cycles.

Follow-up. Follow-up examinations were performed at the Department of Therapeutic Radiology and Oncology, and the Department of Neurology, Medical University of Graz, Austria including cerebral CT/MRI scans every 3 months in years $1-3$, and every 6 months thereafter. Tumor progression was defined as an increase in tumor size by 25 percent or an appearance of new lesions. The median duration of follow-up time for all patients was 11 months (mean: 15 months; range, $1-81$ months).

Salvage Treatment. During follow- up, tumor progression was detected in 180 patients (95\%). In these patients, therapeutic management was performed at the discretion of the treating neuro-oncologist. For tumor progression, $74 \mathrm{pa}-$ tients were administered salvage therapy, 61 patients received chemotherapy. 30 patients had local therapy, nine patients among them underwent re-irradiation (radiosurgery, $\mathrm{n}=5$, hypofractionated stereotactic RT, $\mathrm{n}=4$ ). The remaining 115 patients were offered best supportive care.

Statistical analyses. Statistic analysis was done using SPSS 18.0 for Windows. Numeric values were analyzed by Student's t-test, proportions of groups were compared by chi2-test. Overall survival (OS) time was calculated from the date of biopsy/surgery. Progression-free survival (PFS) was defined as the time from biopsy/surgery until tumor progression. Median time of follow-up was calculated form surgery to last follow up or death. OS as well as PFS were analyzed by calculating cumulative survival rates by the Kaplan-Meier method and evaluating them by the log-rank test. Univariate and multivariate Cox proportional hazards analyses were performed to calculate the hazard ratio (HR) and $95 \%$ confidence interval (CI) to evaluate the influence of prognostic factors on survival. P-values $\leq 0.05$ were considered statistically significant.

\section{Results}

Progression-free survival (PFS). Median PFS was 6 months, actuarial 1 and 2- year PFS rates were 23\% and $7 \%$, respectively. In a Kaplan Meier analysis, extent of tumor resection was significantly associated with disease progression (median PFS was 8 months vs. 6 months vs. 3 months after complete tumor resection vs. incomplete resection vs. biopsy; $\mathrm{p}=0.001$ ).

Furthermore, TMZ therapy significantly influenced PFS (median PFS was 5 months vs. 7 months vs. 9 months for patients without TMZ vs. concomitant TMZ therapy vs. concomitant and adjuvant TMZ, figure 1a-b). Without TMZ, 1 - and 2- year PFS rates were $13 \%$ and $2 \%$, with concomitant TMZ 29\% and $11 \%$, and with concomitant and adjuvant TMZ $42 \%$ and $13 \%$.

Overall survival. Median overall survival (OS) was 13.0 months, actuarial 1- and 2- year OS rates were 54\% and $22 \%$, respectively. OS was significantly influenced by extent of resection (median OS was 16 months vs. 9 months vs. 6 months after complete tumor resection vs. incomplete resection vs. biopsy; $\mathrm{p}<0.001$ ).

Furthermore, a significant association between TMZ therapy and OS was observed (median OS was 11 months vs. 14 months vs. 21 months without TMZ vs. concomitant TMZ therapy vs. 21 months with concomitant and adjuvant TMZ). 

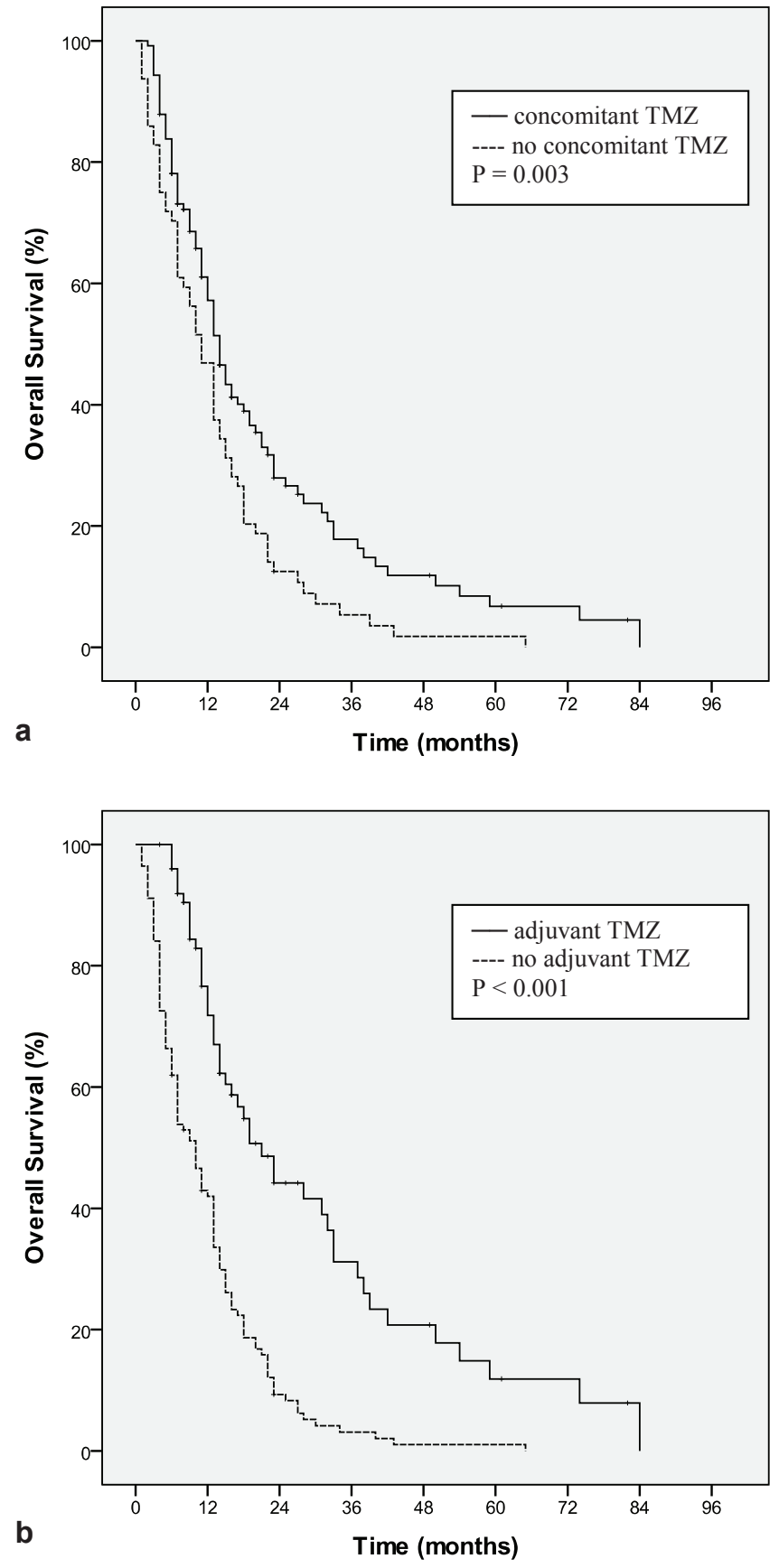

Figure 2a-b. Association of (a) concomitant TMZ and (b) adjuvant TMZ with Overall Survival.

Without TMZ, 1 - and 2- year OS rates were $47 \%$ and $11 \%$, with concomitant TMZ 57\% and 28\%, and with concomitant and adjuvant TMZ $72 \%$ and $44 \%$ (figure $2 \mathrm{a}-\mathrm{b}$ ).

After salvage therapy for disease progression, median OS was 32 months with 1 - and 2 - year OS rates of $80 \%$ and $50 \%$ in patients who had undergone initial concomitant and adjuvant TMZ (figure 3).

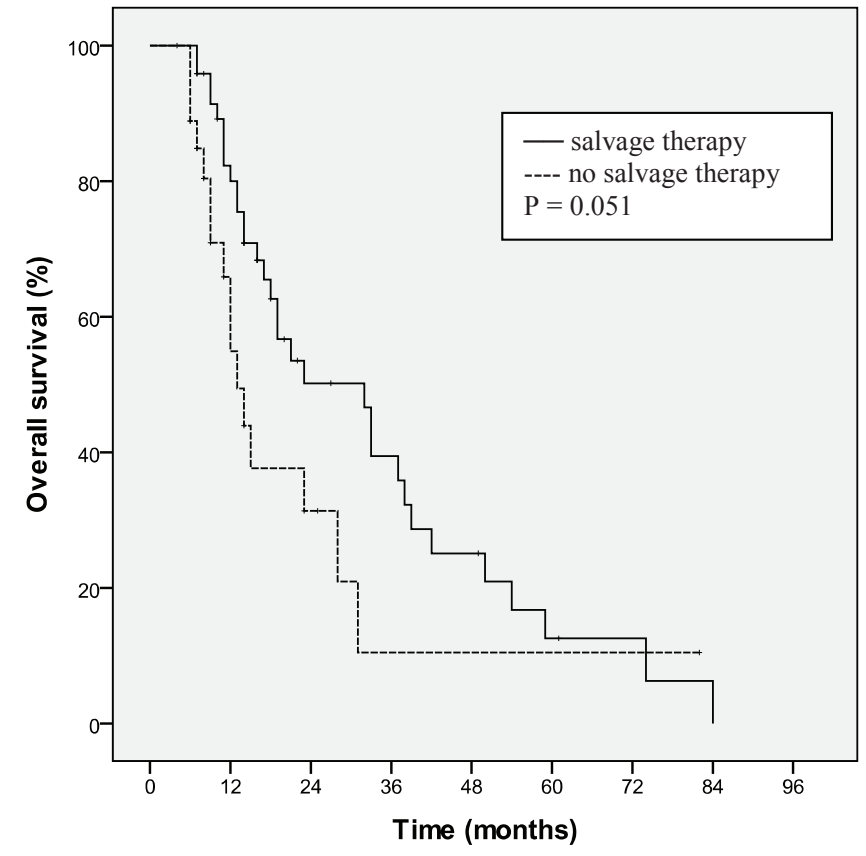

Figure 3. Influence of salvage therapy on Overall Survival in patients with initial concomitant and adjuvant TMZ.

Prognostic factors. The following patient, treatment and tumor characteristics were analyzed for their prognostic impact: age at diagnosis, sex, maximum tumor diameter, number of lesions, extent of tumor resection, time from surgery to start of radiotherapy, KPS, TMZ treatment, and salvage therapy.

Univariate and multivariate analysis revealed that age, extent of tumor resection, and TMZ treatment were significantly associated with PFS whereas the number of lesions was only significant in univariate analysis (table 2). Furthermore, age, KPS, number of lesions, extent of surgery, TMZ treatment, and salvage therapy were significantly associated with OS in univariate analysis. In multivariate analysis, age, extent of surgery, TMZ therapy, and salvage therapy remained significant prognosticators of survival (table 3 ).

Toxicity. In 8 patients, grade $3 / 4$ myelodepression was observed, 2 patients developed elevated liver enzymes and 5 patients infections. Headache was recorded in 8 patients, and a worsening of pre-existing focal neurological deficit was observed in 11 patients. Further acute reactions included fatigue $(n=9)$, nausea $(n=1)$, erythema $(n=1)$, otitis externa $(n=1)$, and deep venous thrombosis $(n=2)$.

RT with concomitant TMZ was well tolerated in the majority of patients and completed as scheduled in 97 of 124 patients (78\%). 23 patients prematurely discontinued RT, additionally, 4 patients discontinued simultaneous TMZ therapy due to grade $3 / 4$ hematologic toxicity $(n=3)$ and herpes infection $(n=1) .21$ patients developed a severe impairment of performance status due to disease progression and were therefore not suitable for adjuvant TMZ that was performed 
Table 2. Univariate and multivariate analyses of prognostic factors for disease progression

\begin{tabular}{|c|c|c|c|c|c|c|}
\hline \multirow[t]{2}{*}{ Prognostic factors } & \multicolumn{3}{|c|}{ Univariate analysis } & \multicolumn{3}{|c|}{ Multivariate analysis } \\
\hline & HR & $95 \% \mathrm{CI}$ & p-value & $\mathrm{HR}$ & $95 \% \mathrm{CI}$ & p-value \\
\hline \multicolumn{7}{|l|}{ Age at diagnosis } \\
\hline Per 10 years & 1.014 & $1.003-1.026$ & 0.015 & 1.017 & $1.004-1.030$ & 0.009 \\
\hline \multicolumn{7}{|l|}{ Sex } \\
\hline Female & 1.000 & & & 1.000 & & \\
\hline Male & 1.089 & $0.806-1.472$ & 0.578 & 1.278 & $0.910-1.795$ & 0.157 \\
\hline \multicolumn{7}{|l|}{ Number of lesions } \\
\hline 1 & 1 & & & 1 & & \\
\hline 2 or more & 2.076 & $1.217-3.540$ & 0.007 & 1.884 & $0.920-3.857$ & 0.083 \\
\hline \multicolumn{7}{|c|}{ Maximum tumor diameter } \\
\hline Per cm & 0.934 & $0.843-1.034$ & 0.189 & 0.940 & $0.846-1.044$ & 0.248 \\
\hline \multicolumn{7}{|l|}{ Surgery } \\
\hline Total & 1.000 & & & 1.000 & & \\
\hline Incomplete & 1.667 & $1.203-2.309$ & 0.002 & 1.759 & $1.202-2.573$ & 0.004 \\
\hline Biospy & 1.768 & $1.133-2.759$ & 0.012 & 2.407 & $1.424-4.069$ & 0.001 \\
\hline \multicolumn{7}{|c|}{ Karnofsky performance score } \\
\hline$\geq 70$ & 1.000 & & & 1.000 & & \\
\hline$<70$ & 1.383 & $0.974-1.962$ & 0.07 & 1.177 & $0.788-1.756$ & 0.426 \\
\hline \multicolumn{7}{|c|}{ Time from surgery to start of RT } \\
\hline Per month & 0.998 & $0.950-1.048$ & 0.925 & 0.977 & $0.927-1.029$ & 0.380 \\
\hline \multicolumn{7}{|l|}{ Temozolomide } \\
\hline No & 1.000 & & & 1.000 & & \\
\hline Yes & 0.409 & $0.298-0.562$ & $<0.001$ & 0.373 & $0.258-0.539$ & $<0.001$ \\
\hline
\end{tabular}

Abbreviations: $\mathrm{HR}=$ Hazard ratio; $\mathrm{CI}=$ Confidence interval

Table 3. Univariate and multivariate analyses of prognostic factors for overall survival

\begin{tabular}{|c|c|c|c|c|c|c|}
\hline \multirow[t]{2}{*}{ Prognostic factors } & \multicolumn{3}{|c|}{ Univariate analysis } & \multicolumn{3}{|c|}{ Multivariate analysis } \\
\hline & HR & $95 \% \mathrm{CI}$ & $\mathrm{p}$-value & HR & $95 \% \mathrm{CI}$ & p-value \\
\hline \multicolumn{7}{|l|}{ Age at diagnosis } \\
\hline Per 10 years & 1.022 & $1.008-1.035$ & 0.001 & 1.027 & $1.012-1.042$ & $<0.001$ \\
\hline \multicolumn{7}{|l|}{ Sex } \\
\hline Female & 1.000 & & & 1 & & \\
\hline Male & 1.083 & $0.778-1.508$ & 0.637 & 1.180 & $0.810-1.718$ & 0.389 \\
\hline \multicolumn{7}{|l|}{ Number of lesions } \\
\hline 1 & 1 & & & 1 & & \\
\hline 2 or more & 2.552 & $1.419-4.588$ & 0.002 & 1.968 & $0.941-4.116$ & 0.072 \\
\hline \multicolumn{7}{|c|}{ Maximum tumor diameter } \\
\hline Per cm & 0.975 & $0.874-1.086$ & 0.641 & 0.966 & $0.863-1.081$ & 0.547 \\
\hline \multicolumn{7}{|l|}{ Surgery } \\
\hline Total & 1.000 & & & 1 & & \\
\hline Incomplete & 1.929 & $1.354-2.745$ & $<0.001$ & 2.025 & $1.329-3.083$ & 0.001 \\
\hline Biospy & 1.989 & $1.242-3.187$ & 0.004 & 3.187 & $1.824-5.569$ & $<0.001$ \\
\hline \multicolumn{7}{|c|}{ Karnofsky performance score } \\
\hline$\geq 70$ & 1.000 & & & 1 & & \\
\hline$<70$ & 1.711 & $1.179-2.483$ & 0.005 & 1.261 & $0.837-1.901$ & 0.268 \\
\hline \multicolumn{7}{|c|}{ Time from surgery to start of RT } \\
\hline Per month & 1.017 & $0.961-1.075$ & 0.564 & 0.985 & $0.926-1.050$ & 0.671 \\
\hline \multicolumn{7}{|l|}{ Temozolomide } \\
\hline No & 1.000 & & & 1 & & \\
\hline Yes & 0.344 & $0.241-0.490$ & $<0.001$ & 0.402 & $0.261-0.620$ & $<0.001$ \\
\hline \multicolumn{7}{|l|}{ Salvage therapy } \\
\hline No & 1.000 & & & 1 & & \\
\hline Yes & 0.446 & $0.319-0.623$ & $<0.001$ & 0.626 & $0.422-0.928$ & 0.020 \\
\hline
\end{tabular}

Abbreviations: $\mathrm{HR}=$ Hazard ratio; $\mathrm{CI}=$ Confidence interval 
in 76 out of 124 patients with radiotherapy and concomitant $\operatorname{TMZ}(61 \%)$.

Premature treatment discontinuitation was significantly influenced by KPS $<70$ prior to start of RT $(\mathrm{p}=0.016)$ whereas a significant influence of other factors such as age $(\mathrm{p}=0.939)$ and extent of surgery $(\mathrm{p}=0.819)$ was not observed.

\section{Discussion}

In this retrospective study, treatment results and prognostic factors were analyzed in an unselected cohort of patients with GMB who were treated from 1999 to 2009. In all patients, 3D conformal radiotherapy was performed, and beginning in 2002, 124 patients received systemic TMZ treatment.

TMZ significantly improved PFS and OS resulting in 1 - and 2- year OS rates of $57 \%$ and $28 \%$. Considering that our patient population represents an unselected group it is notable that the 2- year OS and PFS rates compare favourably with those from the EORTC-NCIC trial with 2-year PFS and OS $10.7 \%$ and $26.5 \%$ in patients with GBM receiving TMZ therapy $[14,15]$.

Additional administration of adjuvant TMZ resulted in a further improvement of survival with 1- and 2- year OS rates of $72 \%$ and $44 \%$. However, a substantial proportion of patients has been observed to be unfit to undergo adjuvant chemotherapy that was applicable in only $61 \%$ of patients after concomitant TMZ in the present study compared with $78 \%$ in the EORTC-NCIC trial [14] .

It is well established that outcome results after treatment of GB are strongly associated with factors such as age, performance status, and extent of surgical resection $[16,17]$ that has also been confirmed in the present investigation.

Incomplete resection and biopsy as the only neurosurgical intervention were significantly associated with poorer survival in univariate as well as in multivariate analysis. Although some studies have failed to demonstrate a survival benefit with more extensive surgical resection versus biopsy alone [18], most reports from single centers or randomized trials support that more extensive resections significantly lengthen OS [5]. Especially patients who undergo surgery at high-volume academic centers appear to have an advantage, as mortality at these centers is very low [19].

In univariate analysis, KPS was significantly associated with survival but it failed to remain a significant prognosticator of survival in multivariate analysis. However, KPS has been shown to significantly influence the patients' ability to undergo treatment as currently recommended. In patients with KPS $<70$, premature discontinuation of treatment has been observed to occur significantly more frequently compared with patients with KPS $\geq 70$. Interestingly, a significant impact of age or extent of surgery on treatment discontinuation has not been observed.

Advanced age is associated with poor survival, therefore, elderly patients frequently receive only best supportive care. However, in case of good performance status, elderly patients have also been shown to benefit from radiotherapy and chemotherapy in previous studies [20,21].

Despite advances in surgery, radiotherapy, and chemotherapy, the prognosis of patients with GBM is still poor and almost all patients ultimately relapse. Salvage treatment such as chemotherapy and local treatment including surgery or reirradiation has been found to significantly improve survival in multivariate analysis. However, even with various salvage treatment regimens, the 6-month progression-free survival rate ranging from $9 \%$ to $21 \%$ is very limited $[22,23]$.

The current study has several limitations, including the limitations of retrospective data collection. Important variables such as MGMT methylation, status, IDH1 mutation status and quality of life measurements were also not available. Nonetheless, the results from the present study show that a combination of maximum surgery, concomitant RCT, and adjuvant TMZ is associated with moderate toxicity and is feasible and effective in daily clinical practice yielding outcome data in unselected patients that are comparable to those achieved in randomized clinical trials.

There is imminent need to develop novel therapeutic strategies which improve outcome in patients with glioblastomas. In a recent study, median overall survival in glioblastoma patients was 28 months when fractionated stereotactic radiotherapy up to doses $>60$ Gy was used in combination with TMZ [24]. In clinical studies, promising results have also been obtained with antiangiogenic therapies, small molecular inhibitors, immunotherapeutic approaches, growth factor receptor targeting, and gene therapies $[4,25]$. Furthermore, molecular analyses may contribute to the development of targeted therapies and identify individual patients that are more likely to respond to a particular therapeutic strategy and improve survival outcomes.

\section{References}

[1] CBTRUS. Statistical report: primary brain tumors in the United States, 2000-2004. Chicago: Central Brain Tumor Registry of the United States; 2008.

[2] WRENSCH M, MINN Y, CHEW T, BONDY M, BERGER MS. Epidemiology of primary brain tumors: current concepts and review of the literature. Neuro Oncol 2002; 4: 278-299.

[3] SCOCCIANTI S, MAGRINI SM, RICARDI U, DETTI B, BUGLIONE $\mathrm{M}$ et al. Patterns of Care and Survival in a Retrospective Analysis of 1059 Patients With Glioblastoma Multiforme Treated Between 2002 and 2007: A Multicenter Study by the Central Nervous System Study Group of Airo (Italian Association of Radiation Oncology). Neurosurgery 2010; 67: 446-458. http: //dx.doi.org/10.1227/01. NEU.0000371990.86656.E8

[4] VAN MEIR EG, HADJIPANAYIS CG, NORDEN AD, SHU HK, WEN PY et al. Exciting new advances in neuro-oncology: the avenue to a cure for malignant glioma. CA Cancer J Clin 2010; 60: 166-193. http: //dx.doi.org/10.3322/caac.20069

[5] SANAI N, BERGER MS. Glioma extent of resection and its impact on patient outcome. Neurosurgery 2008; 62: 753-764. http: //dx.doi.org/10.1227/01.neu.0000318159.21731.cf 
[6] VUORINEN V, HINKKA S, FARKKILA M, JAASKELAINEN J. Debulking or biopsy of malignant glioma in elderly people - a randomised study. Acta Neurochir (Wien) 2003; 145: 5-10. http: //dx.doi.org/10.1007/s00701-002-1030-6

[7] SOUWEIDANE MM, LUTHER N. Endoscopic resection of solid intraventricular brain tumors. J Neurosurg 2006; 105: 271-178. http://dx.doi.org/10.3171/jns.2006.105.2.271

[8] STUMMER W, PICHLMEIER U, MEINEL T, WIESTLER OD, ZANELLA F et al. ALA-Glioma Study Group. Fluorescenceguided surgery with 5-aminolevulinic acid for resection of malignant glioma: a randomised controlled multicentre phase III trial. Lancet Oncol 2006; 7: 392-401. http: //dx.doi. org/10.1016/S1470-2045(06)70665-9

[9] TONN JC, STUMMER W. Fluorescence guided resection of malignant gliomas using 5-aminolevulinic acid: practical use, risks, and pitfalls. Clin Neurosurg 2008; 55: 20-26.

[10] MCDONALD MW, SHU HK, CURRAN WJ JR, CROCKER IR. Pattern of failure after limited margin radiotherapy and temozolomide for glioblastoma. Int J Radiat Oncol Biol Phys 2011; 79: 130-136. http://dx.doi.org/10.1016/ j.ijrobp.2009.10.048

[11] RICKHEY M, MORAVEK Z, EILLES C, KOELBL O, BOGNER L. 18F-FET-PET-based dose painting by numbers with protons. Strahlenther Onkol 2010; 186: 320-326. http: //dx.doi.org/10.1007/s00066-010-2014-8

[12] ROSENSCHOLD PM, ENGELHOLM S, OHLHUES L, LAW I, VOGELIUS I et al. Photon and proton therapy planning comparison for malignant glioma based on CT, FDG-PET, DTI-MRI and fiber tracking. Acta Oncol 2011; 50: 777-783. http: //dx.doi.org/10.3109/0284186X.2011.584555

[13] BODA-HEGGEMANN J, LOHR F, WENZ F, FLENTJE M, GUCKENBERGER M. kV cone-beam CT-based IGRT: a clinical review. Strahlenther Onkol 2011; 187: 284-291. http: //dx.doi.org/10.1007/s00066-011-2236-4

[14] STUPP R, HEGI ME, MASON WP, VAN DEN BENT MJ, TAPHOORN MJ et al. European Organisation for Research and Treatment of Cancer Brain Tumour and Radiation Oncology Groups; National Cancer Institute of Canada Clinical Trials Group. Effects of radiotherapy with concomitant and adjuvant temozolomide versus radiotherapy alone on survival in glioblastoma in a randomised phase III study: 5 year analysis of the EORTC-NCIC trial. Lancet Oncol 2009; 10: 459-466. http: //dx.doi.org/10.1016/S1470-2045(09)70025$\underline{7}$

[15] STUPP R, MASON WP, VAN DEN BENT MJ, WELLER M, FISHER B et al. European Organisation for Research and Treatment of Cancer Brain Tumor and Radiotherapy Groups; National Cancer Institute of Canada Clinical Trials Group. European Organisation for Research and Treatment of Cancer Brain Tumor and Radiotherapy Groups; National Cancer Institute of Canada Clinical Trials Group. Radiotherapy plus concomitant and adjuvant temozolomide for glioblastoma.
N Engl J Med 2005; 52: 987-996. http://dx.doi.org/10.1056/ NEJMoa043330

[16] GORLIA T, VAN DEN BENT MJ, HEGI ME, MIRIMANOFF RO, WELLER $M$ et al. Nomograms for predicting survival of patients with newly diagnosed glioblastoma: prognostic factor analysis of EORTC and NCIC trial 26981-22981/CE.3. Lancet Oncol 2008; 9: 29-38. http: //dx.doi.org/10.1016/S14702045(07)70384-4

[17] BARNHOLTZ-SLOAN JS, WILLIAMS VL, MALDONADO JL, SHAHANI D, STOCKWELL HG et al. Patterns of care and outcomes among elderly individuals with primary malignant astrocytoma. J Neurosurg 2008; 108: 642-648. http: //dx.doi. org/10.3171/JNS/2008/108/4/0642

[18] LACROIX M, ABI-SAID D, FOURNEY DR, GOKASLAN ZL, SHI W et al. A multivariate analysis of 416 patients with glioblastoma multiforme: prognosis, extent of resection, and survival. J Neurosurg 2001; 95: 190-198. http: //dx.doi. org/10.3171/jns.2001.95.2.0190

[19] LONG DM, GORDON T, BOWMAN H, ETZEL A, BURLEYSON $G$ et al. Outcome and cost of craniotomy performed to treat tumors in regional academic referral centers. Neurosurgery 2003; 52: 1056-1063. http: //dx.doi.org/10.1227/01. NEU.0000057745.48813.93

[20] KEIME-GUIBERT F, CHINOT O, TAILLANDIER L, CARTALAT-CAREL S, FRENAY M et al. Association of French-Speaking Neuro-Oncologists. Radiotherapy for glioblastoma in the elderly. N Engl J Med 2007; 356: 1527-1535. http://dx.doi.org/10.1056/NEJMoa065901

[21] CHINOT OL, BARRIE M, FRAUGER E, DUFOUR H, FIGARELLA-BRANGER D et al. Phase II study of temozolomide without radiotherapy in newly diagnosed glioblastoma multiforme in an elderly populations. Cancer 2004; 100: 2208-2214. http: //dx.doi.org/10.1002/cncr.20224

[22] HOFER S, ELANDT K, GREIL R, HOTTINGER AF, HUBER $\mathrm{U}$ et al. Clinical outcome with bevacizumab in patients with recurrent high-grade glioma treated outside clinical trials. Acta Oncol 2011; 50: 630-635. http://dx.doi.org/10.3109/ $\underline{0284186 X .2011 .572913}$

[23] NIYAZI M, SIEFERT A, SCHWARZ SB, GANSWINDT U, KRETH FW et al. Therapeutic options for recurrent malignant glioma. Radiother Oncol 2011; 98: 1-14. http: //dx.doi. org/10.1016/j.radonc.2010.11.006

[24] BALDUCCI M, APICELLA G, MANFRIDA S, MANGIOLA A, FIORENTINO A et al. Single-arm phase II study of conformal radiation therapy and temozolomide plus fractionated stereotactic conformal boost in high-grade gliomas: final report. Strahlenther Onkol 2010; 186: 558-564. http://dx.doi. org/10.1007/s00066-010-2101-X

[25] ADAMSON C, KANU OO, MEHTA AI, DI C, LIN N et al. Glioblastoma multiforme: a review of where we have been and where we are going. Expert Opin Investig Drugs 2009; 18: 1061-1083. http: //dx.doi.org/10.1517/13543780903052764 